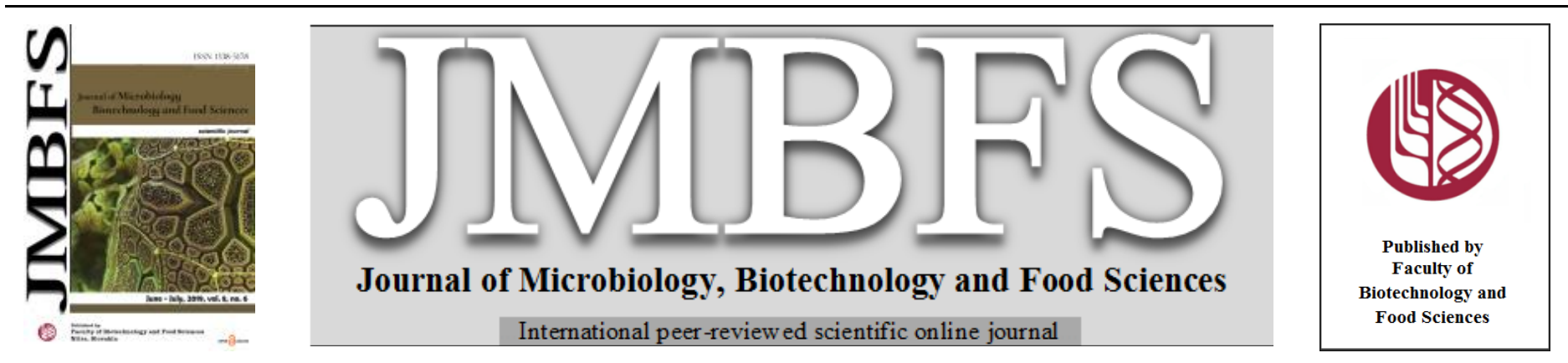

\title{
AN UPDATE ON THE IXODES RICINUS MICROBIOME
}

\author{
Vladimir Kmet' ${ }^{1}$, Zuzana Čaplová ${ }^{2}$ \\ Address(es): prof. MVDr. Vladimir Kmet', DrSc, \\ ${ }^{1}$ Institute of Animal Physiology, Centre of Biosciences, Slovak Academy of Sciences, Šoltésovej 4, 04001 Košice, Slovakia. \\ ${ }^{2}$ Food Research Institute, NPPC, Priemyselná 4, P.O.Box 25, 82475 Bratislava 26, Slovakia.
}

*Corresponding author: kmetv@saske.sk

doi: 10.15414/jmbfs.2019.8.6.1340-1342

ARTICLE INFO

Received 18. 1. 2019

Revised 1. 2. 2019

Accepted 13. 3. 2019

Published 1. 6. 2019

Regular article

open $\partial_{\text {ACCESS }}$

\begin{abstract}
Ixodes ricinus is vector in the transmission of many important infectious diseases in human and animals. There is still minimal information available on the bacterial agents associated with ticks found in Slovakia. We performed a survey of the bacterial communities associated with Ixodes ricinus collected from forest area near a great city aglomeration. Bacterial 16S rRNA hypervariable region amplicon libraries prepared from the Ixodes ricinus females were sequenced on Illumina MiSeq platform. We detected a total of 107 bacterial genera and order Clostridiales and class Bacilli (with more than 100 reads). Dominant taxa included the tick endosymbionts e.g. spotted fever group (Rickettsia 21998 reads) and Coxiella (10715 reads). Second dominant species was mycoplasma Spiroplasma ixodetis (9554 reads).

Dominant enviromental soil bacteria were Pseudomonas (6741 reads), Nocardiodes (4753 reads), Brevundimonas (2797 reads), Devosia (2797 reads) Aureimonas (1398 reads), Actinomycetospora (964 reads), Terrimonas (962 reads), Pedobacter (1139 reads), Methylobacterium (956 reads), Rhodococcus (945 reads), Williamsia (832 reads), Rhizobium (787 reads), Mesorhizobium (631 reads), Rhizobium (602 reads) and Spirosoma (486 reads) .

Firmicutes were only 280 reads with 151 reads of Clostridia and 128 reads of Bacilli (include Staphylococcus and Bacillus ). The cultivation and Maldi Tof analysis revealed seven species of coagulase negative staphylococci (CoNS) i.e., Staphylococcus epidermidis, S. capitis, S.haemolyticus, S.hominis, S. pasteuri, S.chromogenes, S.warneri and Micrococcus luteus. Antibiotic resistant CoNS with $m s r A$ and blaZ genes were detected. Five species of bacilli i.e. Bacillus cereus, B. licheniformis, B. thuringiensis and $B$. mycoides and two species of Brevibacillus i.e. B. parabrevis and B. agri were detected by Maldi Tof, also. The results of the next generation sequencing revealed a new look at the complexity of the Ixodes ricinus microbiome.
\end{abstract}

Keywords: Ixodes ricinus, bacteria, NGS, Maldi tof, Staphylococcus, antibiotic resistance

\section{INTRODUCTION}

Ticks are important vectors of pathogens affecting humans and animals worldwide. They do not only carry pathogens but diverse commensal and symbiotic microorganisms are also present in ticks. A molecular screening for tick-borne pathogens and endosymbionts in Ixodes ricinus, Dermacentor reticulatus and Haemaphysalis inermis from Slovakia revealed the presence of Rickettsia spp., Coxiella burnetii, Coxiella-like and Francisella-like microorganisms (Špitalská et al. 2018). Bielawska-Drózd et al. (2016) detected the presence of Coxiella burnetii in $1,33 \%$ of Poland ticks $1,33 \%$ by real time PCR of IS1111 gene sequence. Egyed and Makrai (2014) found that the most frequent bacteria isolated from three tick species were Staphylococcus $(18.1 \%)$ and Bacillus (7.8\%). Coagulase-negative staphylococci (CoNS) have become increasingly recognized as important agents of skin infections (Sader et al. 2010). However there are no data available about antimicrobial resistance of staphylococci isolated from ticks.

In recent years the number of studies, mostly from USA, Australia and China, using NGS to investigate the microbial diversity and composition of ticks has expanded (Greay et al. 2018). However in Europe only from France (VayssierTaussat at al. 2013) and northern Italy (Carpi et al. 2011) NGS of Ixodes ricinus was used. The aim of this study was to describe the microbiome data of Ixodes ricinus microbiome by next generation sequencing and by cultivation experiments in Slovakia.

\section{MATERIAL AND METHODS}

\section{Ticks, DNA isolation and bacterial cultivation}

Ticks of Ixodes ricinus ticks were collected by flagging near a city agglomeration characterised by the presence of sylvatic deciduous forest. Females of ticks were sampled in $96 \%$ ethanol, rinsed in saline and homogenised.
DNA was extracted by commercial kit (DNAeasy tissue kit, Qiagen, Hilden Germany). Homogenised ticks were cultivated overnight in Nutrient broth (Oxoid Ltd, UK) at $37^{\circ} \mathrm{C}$. Broth cultures were inoculated on Mannitol Salt agar (Oxoid Ltd, UK) and on blood agar (containing $10 \%$ defibrinated sheep blood). Suspect colonies were detected by MALDI-TOF biotyper (Bruker Daltonics).

\section{Next generation sequencing}

Bacterial 16S rDNA were amplified using primers 27F (5'-AGA GTT TGA TCM TGG CTC AG-3') and 1062R (5'-ACA GCC ATG CAG CAC CT-3') to amplify V1-V6 hypervariable regions (Ghyselinck et al. 2013). The reaction mixture $(25 \mu \mathrm{l})$ contained $1.25 \mathrm{U}$ thermostable DNA polymerase (Cheetah Hot Start Taq Polymerase; Biotium, Hayward, California, USA), $1 \times$ buffer supplied with the polymerase, $1,5 \mathrm{mmol} .1^{-1} \mathrm{MgCl}_{2}, 340 \mu$ mol.1 ${ }^{-1}$ dNTP (Applied Biosystems) and 300 nmol.1 ${ }^{-1}$ each primer. PCR was carried out in a Veriti thermal cycler (Applied Biosystems, Foster City, California, USA) using a program for $16 \mathrm{~S}$ region consisting of initial denaturation at $94{ }^{\circ} \mathrm{C}$ for $2 \mathrm{~min}, 35$ cycles (denaturation at $94{ }^{\circ} \mathrm{C}$ for $1 \mathrm{~min}$, annealing at $54{ }^{\circ} \mathrm{C}$ for $1 \mathrm{~min}$ and extension at $72{ }^{\circ} \mathrm{C}$ for $2 \mathrm{~min}$ ) and final extension at $72{ }^{\circ} \mathrm{C}$ for $10 \mathrm{~min}$. Amplified products were analysed by agarose gel electrophoresis.

Products of PCR were pooled and purified by QIAquick PCR Purification Kit (Qiagen). Purified PCR products were diluted to equimolar concentration suitable for library preparation and were used as template for library preparation using transposon based Nextera Library preparation kit (Illumina, San Diego, CA, USA) according to standard protocol. Samples were analysed using paired end sequencing on Illumina MiSeq sequencing system (Illumina) in the University Science Park (Komenského University, Bratislava). Sequencing data were imported into CLC Genomics Workbench Version 7.5 (Qiagen). Each sequence of sample were marging and trimming. Limit of trimming using quality score was set to 0.001 and reads shorter than 100 nucleotides were discarded. Reads were identified based on their homology to reference $16 \mathrm{~S}$ rRNA genes in NCBI 
database using Basic Local Alignment Search Tool (BLAST) (Altschul et al. 1990). BLAST results were exported to MEtaGenome ANalyzer (MEGAN V5) (Huson et al., 2011).

\section{Minimal inhibitory concentrations (MIC) and PCR}

Susceptibility (MIC) was determined by Miditech (Bratislava) colourimetric broth microdilution method (http://www.eucast.org/), using ampicillin (AMP), oxacillin (OXA), moxifloxacin (MFX), erythromycin (ERY), clindamycin (CLI), linezolid (LND), tetracycline (TTC), chloramphenicol (CMP), trimethoprim (TRI), rifampicin (RIF) and teicoplanin (TEC). The presence of antibiotic resistance genes mecA and $m e c C$ (meticillin resistance), blaZ (beta-lactamase), erm $C$ (macrolide resistance), $m s r A$ (efflux), dfrS (trimethoprim resistance) were determined by PCR (Kmet et al. 2018).

\section{RESULTS AND DISCUSSION}

NGS data (154995 sequences) were analyzed to identify relative abundance of microorganisms by phylum down to genus levels. Proteobacteria were in greatest abundance, followed by Actinobacteria, Tenericutes and Bacteroidetes. The Ixodes ricinus mixed DNA sample showed sequence homology with 107 bacterial genera and order Clostridiales and class Bacilli (with more than 100 reads).

Figure 1 shows the occurrence of individual species of bacteria in the microbiome Ixodes ricinus, the size of which represents the percentage of individual readings. Dominant taxa include the tick endosymbionts e.g. spotted fever group (Rickettsia 21998 reads) and Coxiella (10715 reads). Second dominant species was mycoplasma Spiroplasma ixodetis (9554 reads). Dominant enviromental soil bacteria were Pseudomonas (6741 reads), Nocardiodes (4753 reads), Brevundimonas (2797 reads), Devosia (2797 reads) Aureimonas (1398 reads), Actinomycetospora (964 reads), Terrimonas (962 reads), Pedobacter (1139 reads), Methylobacterium (956 reads), Rhodococcus (945 reads), Williamsia (832 reads), Rhizobium (787 reads), Mesorhizobium (631 reads), Rhizobium (602 reads) and Spirosoma (486 reads). Firmicutes were only 280 reads with 151 reads of Clostridia and 128 reads of Bacilli (include Staphylococcus and Bacillus).

In the largest group causing a spotted fever group, there are 26 species of rickets (Parola et al. 2013). Typical symptoms of rickettsiosis include fever, rash, and headache. Spiroplasmas are helical mycoplasmas that infect plants and/or arthropods and may be pathogenic or commensal. A previous study in Slovakia reported an overall prevalence of Spiroplasma ixodetis of 3\% in Ixodes ricinus (Bell-Sakyi et al. 2015). Williamsia spp. have been isolated from immunocompromised patients with diabetes mellitus, as well as in elderly patients (Keikha 2018). Rhodococcus, Staphylococcus and Pseudomonas were detected in ixodid ticks (Rudolf et al. 2009). Non-fermenting Gram-negative Brevundimonas spp. bacteraemia was detected in seventeen individual cases (Ryan, Pembroke 2018). Aureimonas altamirensis is an aerobic Gram-negative aerobe related to Brucella species, which is a potential opportunistic pathogen of humans (Eshaghi et al. 2015)

It remains uncertain whether ubiquitous bacteria associated with soil, plants and skin that are frequently reported in NGS studies of ticks are contaminants from environmental or host sources, or whether they are genuinely associated with the tick microbiome (Greay et al. 2018). The cultivation experiments showed the presence of staphylococci and bacilli in ethanol sterilised ticks. Maldi tof analysis revealed seven species of coagulase negative staphylococi i.e. S.epidermidis and S. capitis, S.haemolyticus and S.hominis, S. pasteuri, S.chromogenes, S.warneri and Micrococcus luteus. Five species of bacilli i.e. Bacillus cereus, B. licheniformis , B. thuringiensis and B. mycoides and two species of Brevibacillus i.e. B. parabrevis and B. agri were detected also.

Surprisingly majority CoNS were resistant to erythromycin, some staphylococci were resistant to ampicillin and oxacillin, rarely were resistant to trimethoprim and teicoplanin. However only blaZ and $m s r A$ genes were detected in selected coagulase negative staphylococci from Ixodes ricinus (Table 1). The mecA or mecC genes in phenotype positive meticillin resistant CoNS was not detected, probably due to low level of oxacillin MIC90. Antibiotic resistant coagulasenegative staphylococci can be transmitted from ticks to humans. This study indicates an important role of ixodid ticks as a indicators of antibiotic resistant staphylococci with $m s r A$ and blaZ genes. There is possible a direct relationship between ixodid ticks and their hosts of small mammals, which also carried erythromycin and oxacillin resistant staphylococci (Kmet et al. 2018).

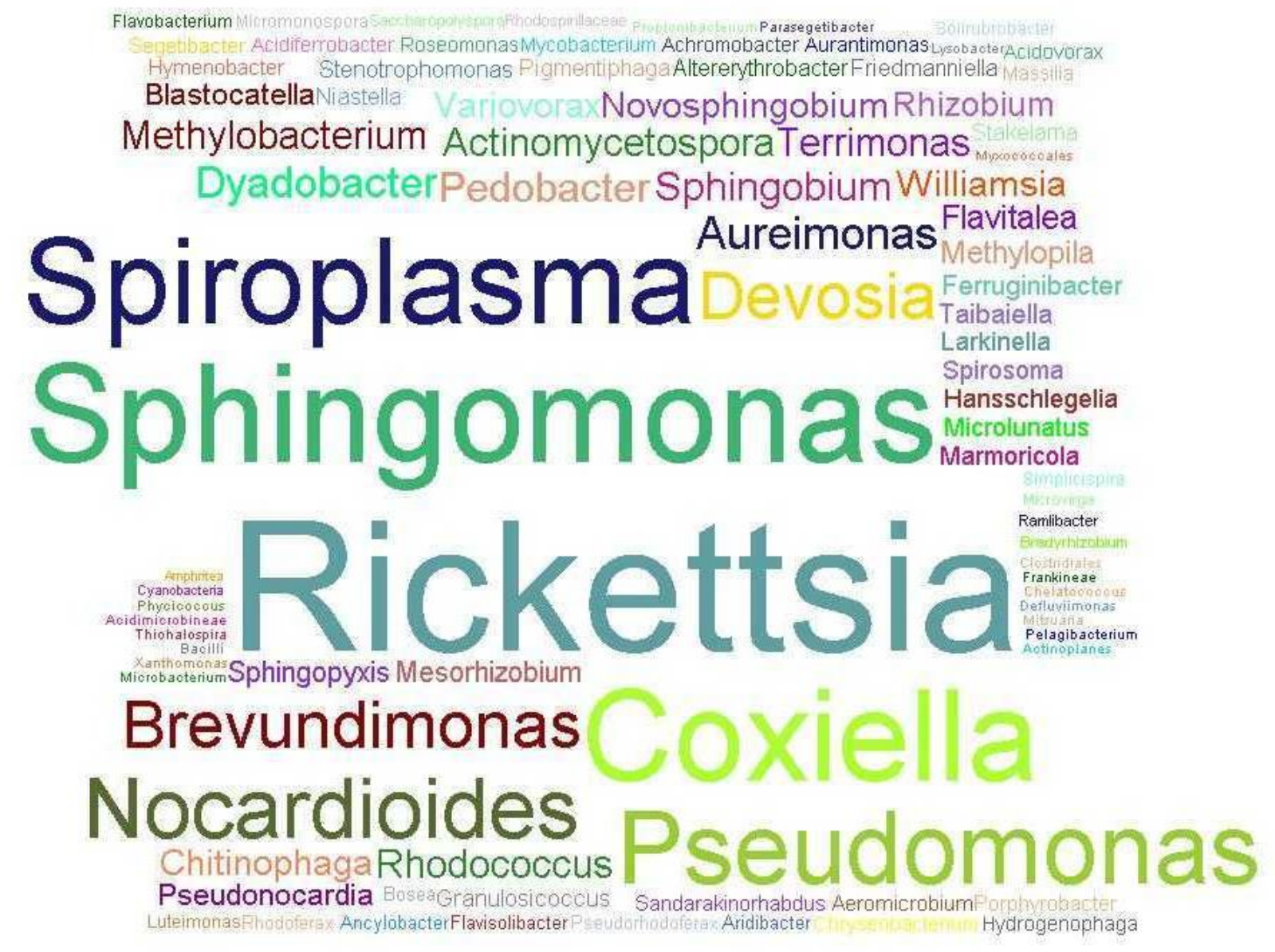

Figure 1 The occurrence of individual genera of bacteria in the microbiome Ixodes ricinus (the size represents the individual readings) 
Table 1 Antibiotic resistance of selected coagulase negative staphylococci from Ixodes ricinus

\begin{tabular}{lll}
\hline Species & Phenotype/Intepretation & PCR \\
\hline & & \\
S. epidermidis & ERY & $m s r A$ \\
S. epidermidis & AMP, ERY & $m s r A$, blaZ \\
S. chromogenes & AMP, ERY, TEC & $m s r A$, blaZ \\
S. haemolyticus & OXA, ERY, TMP, MRCoNS & $m s r A$ \\
S. haemolyticus & OXA, ERY, TEC, TMP, MRCoNS & $m s r A$ \\
S. pasteuri & ERY & $m s r A$ \\
S. warneri & ERY & $m s r A$ \\
\hline
\end{tabular}

\section{CONCLUSION}

The results of the next generation sequencing and cultivation revealed a new look at the complexity of the tick microbiome. Proteobacteria were in greatest abundance, followed by Actinobacteria, Tenericutes and Bacteroidetes. Dominant taxa included the tick endosymbionts (Rickettsia and Coxiella), Spiroplasma ixodetis and environmental soil bacteria. However, only a minor part of the cultivable Staphylococcus and Bacillus were detected. Antibiotic resistant CoNS with $m s r A$ and blaZ genes were detected from ixodid ticks, which appear to be useful indicators of antibiotic resistance in the environment.

Acknowledgements: Authors thank Doc. RNDr. Michal Stanko DrSc of the Parasitology Institute of Slovak Academy od Sciences, Košice for tick collection. This study was supported by Slovak grant APVV-14-0274.

\section{REFERENCES}

Altschul, S. F., Gish, W., Miller, W., Myers, E. W., Lipman, D. J. (1990) Basic local alignment search tool. J Mol Biol. 215(3), 403-410 https://doi.org/10.1016/S0022-2836(05)80360-2

Bell-Sakyi L, Palomar A.M, Kazimirova M. (2015) Isolation and propagation of a Spiroplasma sp. from Slovakian Ixodes ricinus ticks in Ixodes spp. cell lines. Ticks Tick Borne Dis. 6(5):601-6. https://doi.org/10.1016/j.ttbdis.2015.05.002

Bielawska-Drózd, A.,Cieślik, P.,Wlizło-Skowronek, B., Zięba, P., Pitucha, G., Gaweł, J., Knap, J. (2016). Studies on the occurrence of Coxiella burnetii infection in ticks in selected eastern and central regions of Poland. $\mathrm{J}$ Microbiol Biotechnol Food Sciences $\quad$ 5(4) 355-357, https://doi.org/10.15414/jmbfs.2016.5.4.355-357

Egyed, L., Makrai, L.(2014) Cultivable internal bacterial flora of ticks isolated in Hungary. Exp Appl Acarol. 63(1),107-122, https://doi.org/10.1007/s10493-0139762-y

Eshaghi. A., Shahinas, D., Patel, S.N., Kus, J.V. (2015) First draft genome sequence of Aureimonas altamirensis, isolated from patient blood culture. FEMS Microbiol Lett. 362(6). pii: fnv016. https://doi.org/10.1093/femsle/fnv016

Carpi G., Cagnacci F., Wittekindt N.E., Zhao F., Qi J., Tomsho P., Drautz DI, Rizzoli A, Schuster SC. (2011). Metagenomic profile of the bacterial communities associated with Ixodes ricinus ticks. In: PLoS One. 6:e25604. https://doi.org/10.1371/journal.pone.0025604

Ghyselinck, J., Peiffer, S., Heylen, K., Sessitsch, A., de Vos, P. (2013) The effect of primer choice and short read sequences on the outcome of $16 \mathrm{~S}$ rRNA gene based diversity studies. PLoS one, 8, 2013, e71360. https://doi.org/10.1371/journal.pone.0071360

Greay, T.L., Gofton, A.W., Paparini, A., Ryan, U.M., Oskam, C.L., Irwin, P.J. (2018) Recent insights into the tick microbiome gained through next-generation sequencing. Parasit Vectors. 11(1):12. https://doi.org/10.1186/s13071-017-2550$\underline{5}$

Huson, D. H., Mitra, S., Ruscheweyh, H.J., Weber, N., Schuster, S. C. (2011) Integrative analysis of environmental sequences using Megan 4. Genome Res. 21(9), 1552-1560. https://doi.org/10.1101/gr.120618.111

Keikha M. (2018) Williamsia spp. are emerging opportunistic bacteria. New Microbes New Infect. 24, 21, 88-89. https://doi.org/10.1016/j.nmni.2017.11.002 Kmet',V., Čuvalová, A., Stanko, M. (2018). Small mammals as sentinels of antimicrobial-resistant staphylococci. Folia Microbiol. (Praha) 63(5), 665-668. https://doi.org/10.1007/s12223-018-0594-3

Parola, P., Paddock, C.D., Socolovschi, C., Labruna, M.B., Mediannikov, O., Kernif, T., Abdad, M.Y., Stenos ,J., Bitam, I., Fournier, P.E., Raoult, D. (2013) Update on tick-borne rickettsioses around the world: a geographic approach. Clin Microbiol Rev. 26(4),657-702. https://doi.org/10.1128/CMR.00032-13

Rudolf, I., Mendel, J., Sikutová, S., Svec, P., Masaríková, J., Nováková, D. Bunková, L., Sedlácek, I., Hubálek Z. (2009) 16S rRNA gene-based identification of cultured bacterial flora from host-seeking Ixodes ricinus, Dermacentor reticulatus and Haemaphysalis concinna ticks, vectors of vertebrate pathogens. Folia Microbiol.
https://doi.org/10.1007/s12223-009-0059-9

(Praha)

$54(5), 419-428$

Ryan, M.P., Pembroke, J.T. (2018) Brevundimonas spp: Emerging global $\begin{array}{lll}\text { opportunistic } & \text { pathogens. } & \text { Virulence. }\end{array}$ https://doi.org/10.1080/21505594

Sader, H.S., Farrell, D.J., Jones, R.N.(2010) Antimicrobial susceptibility of Gram-positive cocci isolated from skin and skin-structure infections in european medical centres. Int $\mathbf{J}$ Antimicrob Agents 36(1), 28-32. https://doi.org/10.1016/j.ijantimicag.2010.03.016

Špitalská, E., Sparagano ,O., Stanko, M., Schwarzová, K., Špitalský, Z., Škultéty, L., Havlíková, S.F. (2018) Diversity of Coxiella-like and Francisella-like endosymbionts, and Rickettsia spp., Coxiella burnetii as pathogens in the tick populations of Slovakia, Central Europe. Ticks Tick Borne Dis. 9(5),1207-1211. https://doi.org/10.1016/j.ttbdis.2018.05.002

Vayssier-Taussat, M., Moutailler, S., Michelet, L., Devillers, E., Bonnet, S., Cheval, J., Hébert, C., Eloit, M. (2013) Next generation sequencing uncovers unexpected bacterial pathogens in ticks in Western Europe. PLoS One. 8:e81439. https://doi.org/10.1371/journal.pone.0081439 